\title{
Left Atrial Appendage Exclusion in Patients with Atrial Fibrillation: Should it become Standard of Care?
}

\author{
Michael Magarakis ${ }^{1}$ and Panagiotis Sarris-Michopoulos ${ }^{2}$ \\ ${ }^{1}$ Miami VA Medical Center - University of Miami Miller School of Medicine \\ ${ }^{2}$ University of Miami Miller School of Medicine
}

September 25, 2021

\begin{abstract}
Atrial Fibrillation (AF) is the most common arrhythmia affecting the general population, with the prevalence projected to reach 12.1 million cases in 2030. Recently, attention has focused on the role of the Left Atrial Appendage (LAA) and its association with the most feared complication of AF: thromboembolism. Common sense indicates that the LAA should be excluded in all patients with AF; however, procedures to exclude the LAA have yet to become the standard of care. Recent studies in the cardiac surgery literature, , indicate a clear benefit of LAA exclusion amongst patients with AF undergoing cardiac surgery. Interestingly, this benefit was found to extend well beyond the postoperative period, in cohorts that were equally anticoagulated and had similar CHA2DS2-VASC scores. It appears reasonable that our medical community should strongly consider initiating a prospective randomized trial in an effort to fully elucidate the need for routine LAA exclusion in this patient population.
\end{abstract}

\section{Hosted file}

JCS Editorial LAAO revised.doc available at https://authorea.com/users/322287/articles/ 539102-left-atrial-appendage-exclusion-in-patients-with-atrial-fibrillation-should-itbecome-standard-of-care 